\title{
A Glance into Interactions in Some South African Township Mathematics Classrooms
}

\author{
Mapula G Ngoepe \\ Department of Mathematics Education \\ University of South Africa (UNISA), PO Box 392 Pretoria 0003 \\ ngoepmg@unisa.ac.za
}

\section{Doi:10.5901/mjss.2013.v4n13p435}

\begin{abstract}
This paper examines the classroom interactions between teachers and students in some secondary mathematics classrooms in South Africa. Cases of twelve lessons of eight teachers were analyzed using the Secondary Teaching Analysis Matrix framework of Gallagher and Parker (1995) to classify teaching into didactic, transitional and conceptual teaching about classroom interactions. Classroom interactions were found to be predominantly didactic. This means among other things that there was little student interaction about the subject matter; short answers predominated; there were few student questions and student-student interaction was rare. The findings will be used for professional development intervention programs to guide teachers to improve dialogue during mathematics instruction.
\end{abstract}

Keywords: Interactions, township schools, mathematics classrooms, secondary teaching, analysis matrix, student achievement

\section{Introduction}

Research tells us that student interaction - through classroom discussion and other forms of interactive participation - is foundational to deep understanding and related student achievement (Bruce, 2007; Good \& Brophy, 2008). The communication standard, in the Principles and standards for school mathematics as captured in the National Council of Teachers of Mathematics (NCTM) points to the importance of a leaner being able to talk about, write about, describe, and explain mathematical ideas. Therefore, learning to interact in class fosters communication and exploration of ideas because students learn through active engagement. This importance is further emphasized by Van de Walle (2013:4.) when he posits, "no better way exists for wrestling with or cementing an idea than attempting to articulate it to others". Thus communication/interaction in a mathematics class is about a learner being able to explain ideas in writing using words, pictures and numbers, in precise language, units and labeling to clearly communicate ideas (Van de Walle, 2013:80).

According to Bruce, teaching styles that emphasize student interaction, improve both problem solving and conceptual understanding - without loss of computational mastery. The benefits increase further when students share their reasoning with one another and with the teacher. Besides, higher order questions are correlated with increased student achievement, in particular, conceptual understanding. Consequently, mathematics teachers need to create various opportunities for students to interact in class to promote conceptual understanding of mathematics concepts.

\section{Literature Review}

\subsection{Classroom interactions}

Classroom interaction is one of the basic ways by which the teacher stimulates student thinking and learning (Gall, 2013). It is described as a major component of classroom discourse and a vehicle for increasing student learning. According to Gall, the types of questions that should be asked in a mathematics class to encourage interaction, which existing taxonomies do not cover should take account of:

a. questions which prompt students to improve on an initially weak response to a question ("Can you tell me a little more?"; "What do you mean by that?");

b. questions which create a discussion atmosphere ("Tilly, do you agree with Sophie's position?");

c. questions which stimulate students' sense of curiosity and inquiry ("What would you like to know about this word or problem?"; "How would you propose to find an answer to this question?"); and 
d. questions which guide students' learning of a problem-solving, behavioral or affective skill ("What do you think we should do next to solve this problem?"; "Sipho, what is your response to these drawings?").

However, implementing the asking of these kinds of questions in a mathematics classroom would be challenging to township teachers in this study.

\subsection{Teacher's role in promoting interaction in a mathematics classroom}

Researchers generally agree that mathematics teachers should emphasize the development of students' skills in critical thinking rather than in learning and recalling facts (Ebiendele, 2012; Riegle, 1976; Gall, 2013). Some of the specific skills encouraged by the National Curriculum Assessment Policy Statement (CAPS) in South Africa are listed as: learners should be able to learn to listen, communicate, think, reason logically and apply the mathematical knowledge gained (Department of Basic Education, 2013). Student talk and how teachers can foster productive talk, appear explicitly or implicitly in nearly all of the NCTM standards for teaching mathematics, for example

Standard 2 of the NCTM, The Teacher's Role in Discourse, recommends that teachers orchestrate discourse by "posing questions and tasks that elicit, engage and challenge each student's thinking; listening carefully to students' ideas; asking students to clarify and justify their ideas orally and in writing; deciding what to pursue in depth from among the ideas that students bring up during a discussion; deciding when and how to attach mathematical notation and language to students' ideas; deciding when to provide information, when to clarify an issue, when to model, when to lead, and when to let a student struggle with a difficulty; monitoring students' participation in discussions and deciding when and how to encourage each student to participate" (NCTM, 1991, p. 35).

Standard 3, Students' Role in Discourse, calls for the teacher to promote classroom discourse in which "students listen to, respond to, and question the teacher and one another; use of variety of tools to reason, make connections, solve problems, and communicate; initiate problems and questions; make conjectures and present solutions; explore examples and counterexamples to investigate a conjecture; try to convince themselves and one another of the validity of particular representations, solutions, conjectures, and answers" (NCTM, 1991, p. 45).

This means that the teachers should organize mathematics classrooms to function as a community where thinking, talking, agreeing and disagreeing are encouraged. It is expected of a teacher to provide students with powerful mathematics problems to solve together and students are expected to justify and explain their solutions to one another and to the teacher (Department of Basic Education, 2013). A study of effective teachers in Ontario, Canada who successfully facilitated interactions were those who:

a. assigned tasks that required students to work together to develop joint solutions and problem-solving strategies;

b. provided instructions on and modelled expected behaviours focusing on group skills, shared leadership, and effective math communication;

c. urged students to explain and compare their solutions and solution strategies with peers;

d. encouraged students to be both supportive and challenging with peers. (Artzt, Armour-Thomas \& Curcio, 2008)

Left to their own strategies, students will not necessarily engage in high-quality math-conversation. The teacher plays an important role in orchestrating dialogue in a mathematics classroom (Bruce, 2007). However, teacher-centered mathematics classrooms are still a reality in many mathematics classrooms in South Africa, given the prevalence of under qualified and unqualified teachers, under-resourced large classes, existence and dominance of authoritarian modes of interaction and transmission teaching (Taylor \& Vinjevold, 1999). Consequently, it would be quite a challenge to implement effective classroom interaction in South African township schools.

\subsection{The teaching styles as described in the Secondary Teaching Analysis Matrix (STAM)}

Didactic teaching is associated with the telling or lecture method. That means the teacher-centered teaching happens in a highly teacher dominated environment. The central issue here is the transfer of information by means of facts. The assessment serves grading and is designed such that it will assess whether the students received the transmitted information or facts. Students are for the most part passive. Teachers who use didactic methods have very limited concern about students' ideas and reasoning when they prepare their lessons. Usually teachers use didactic methods because they are accustomed to them (most probably they were lectured to at tertiary institutions). Didactic methods allow easy control over students (Duggan-Haas \& Gallagher, 2004) 
Transitional teaching is a teaching style that lies between didactic and conceptual teaching. The content is less fact-centered and more elaborated than in didactic teaching. The teachers' actions show more attention to students' reactions to their presentation. In transitional teaching there will be greater occurrences of teacher-student interaction about content than in didactic teaching. According to Duggan- Haas \& Gallagher, the lecture discussion typically replaces a straight lecture. This instructional practice as Duggan-Haas \& Gallagher maintain, is frequently seen in secondary classrooms as teachers present information to students and then ask them questions about it or respond to students' questions.

Conceptual teaching differs from didactic teaching in each of the dimensions of STAM. Teachers' actions focus more on helping students to develop understanding of relationships and connections. The teacher gives more attention to students' ideas and reasoning, and also uses assessment as a tool for diagnosing students' understanding instead of only using assessment to assign grades. The teacher - student interactions focus on nurturing the development of understanding of mathematics concepts and students' reasoning about them (Duggan-Haas \& Gallagher, 2004).

\section{Research Methodology}

A case study was used to identify and characterize classroom interactions between teachers and students using the Secondary Teaching Analysis Matrix (STAM) framework of Gallagher and Parker (1995). According to Cohen and Manion (2011), the interpretive, subjective dimensions of educational phenomena are best explored by case study methods. Case study method is a preferred strategy when the investigator has little control over events and when the focus is on contemporary phenomenon within some real life context (Yin, 2009). For this reason case study method has been used in this study because it is the most appropriate format for conducting school-based research. For this study, a case entailed descriptions of individual teacher's instructional practices. To conduct the inquiry, classroom observations and video records of lessons were used. Twelve lessons of eight teachers were analyzed using the adapted framework of Gallagher and Parker (1995). STAM consists of rows which are numbered from 1-22 and columns which are labeled A to $F$ to denote the six categories from didactic $(A)$, transitional $(B)$, conceptual $(C)$, early constructivist $(D)$, experienced constructivist (E) to constructivist inquiry $(F)$.

The framework was truncated to a three pronged continuum of using the columns labeled A-C. These denoted the three categories, namely, didactic (STAM A), transitional (STAM B), and conceptual (STAM C) teaching. The reason for adapting the framework was that these three teaching styles were found to be more appropriate for the South African classrooms. The other teaching styles were more inclined to constructivist teaching. Informed by the literature, research with pre-service and practicing teachers, there was little evidence of constructivist teaching in studies of South African classrooms. Also, the lessons of these teachers were chosen because they had enough information that could be analyzed using the STAM instrument. This adapted framework with 22 re-ordered rows and 3 columns was used to carefully analyze the observed lessons in the study. Pseudonyms were used to identify the teachers. To facilitate analysis the lesson was divided into parts to enable identification of the teaching style. The analysis comprised of qualitative descriptions of lesson proceedings. This article presents only data that identified interactions in the classroom using the STAM descriptors STAM7, STAM 12, STAM 13, STAM 14, STAM 15 and STAM 16.

\section{Findings and Discussions}

The following table provides a summary of the interactions in the classrooms of eight teachers which have been identified by using six descriptors of the STAM framework namely:

7. Teacher student interactions

12. Writing and other representations of ideas

13. Students' questions

14. Student-student interaction

15. Student initiated-activity

16. Student understanding of teacher expectations

Summary of analysis on interactions using the adapted framework of Gallagher \& Parker (1995) 


\begin{tabular}{|l|c|c|c|c|c|c|}
\hline \multirow{2}{*}{ Teacher } & \multicolumn{6}{|c|}{ Interaction between the teacher and students } \\
\cline { 2 - 7 } & 7 & 12 & 13 & 14 & 15 & 16 \\
\hline Mr. Timba & T & D & D & D & D & D \\
\hline Ms Mogotse & D & T & D & D & D & D \\
\hline Ms. Makola & D & T & D & D & D & D \\
\hline Mr. Mosotho & D & T & D & D & D & D \\
\hline Mr. Lekgau & D & D & T & D & D & T \\
\hline Mr. Nare & D & D & D & T & D & D \\
\hline Mr. Mosotho & D & D & D & D & D & D \\
\hline Mr. Muntu & D & D & D & D & D & D \\
\hline Mr. Naka & D & 7 & D & D & D & D \\
\hline Mr. Nare & D & D & D & D & D & D \\
\hline Mr. Naka & D & D & D & D & D & D \\
\hline Mr. Muntu & D & D & D & D & D & D \\
\hline
\end{tabular}

On the whole, out of the 12 teachers' lessons that were analyzed using the Secondary teaching analysis matrix, as can be seen in the table above, the interactions between the teacher and the students were found to be predominantly didactic (D). This meant that there was little student interaction about subject matter (STAM 7A); short answers predominated (STAM 12A); there were few student questions (STAM 13A); student-student interaction was rare (STAM 14A); students rarely volunteered examples or analysis (STAM 15A); students were passive and ignored the teachers' procedures (STAM 16A). However, the teaching was identified as having aspects of minimal transitional attributes (T). For example with teacher-student interaction (STAM $7 A B^{1}$ ) only one lesson [Mr. Timba's lesson], had attributes of transitional teaching style, when the teacher attempted to ask questions that led to students correcting their ideas or when the teacher gave learners an opportunity to ask questions for clarification of procedures about problem solutions in his lesson.

With writing and other representations of ideas (STAM 12 AB) four lessons [Mr. Mogotse, Mr. Makola, Mr. Mosotho and Mr. Naka], were identified as having minimal attributes of transitional teaching style. Full details of the lessons can be found in Ngoepe (2003). Transitional attributes were characterized according to STAM by the rare use of writing and other representations of ideas. Most of the writings were reconfigurations of information provided by the teacher. As far as students' questions (STAM 13 AB) were concerned, one lesson had transitional teaching [Mr. Lekgau]. This was when students' questions were dominated by questions that asked for clarification of procedures, terminology or repeat of information. Student-student interaction (STAM 14AB) was identified in one lesson [Mr. Nare]. The studentstudent interactions, were mostly about procedure. None of the lessons (STAM 15AB) had student initiated- activities.

\section{Conclusion}

The paper aimed at examining the interaction between teachers and students using the STAM descriptors. The interaction was identified as being predominantly didactic with very minimal transitional style attributes. None of the lessons were identified as having conceptual attributes.

Due to the Apartheid system of education in the past, the background of teachers and the teacher training conditions in South Africa, the results are not surprising. It would be more desirable to have the interactions manifesting teaching styles with transitional and conceptual forms with several descriptors. In this way teaching would be more towards conforming to learner-centered forms of learning and teaching as advocated by the present South African education system. Even though the sample used to examine the classroom interaction was small, the results provided a glance into the classroom interaction of township schools. Informed by this research, it is recommended that future research focus on finding ways of improving teacher-student interactions; encouraging students to ask questions and interact with each other, initiate classroom activities and volunteer to give solutions to problems.

\section{References}

Artzt, A.F., Armour-Thomas, E., \& Curcio F.R (2008).The Effective Mathematics Classroom. www.ipsi.utexas.edu/docs/.../Admin \%20white\%20paper_NL_2-1-10.pdf.Retrieved 30-08-2013.

Bruce, C. D. (2007).Student Interaction in the Math Classroom: Stealing Ideas or Building Understanding. http://www.edu.gov.on.ca

${ }^{1}$ Note that in order to show the presence of transitional attributes, the descriptor was identified as STAM AB 
/eng/literacynumeracy/inspire/research/bruce.pdf. Retrieved 26-08-2013.

Cohen, L., \& Manion, L. (2011). Research methods in education. London: Routledge Falmer.

Department of Education ( 1997). Curriculum 2005: Lifelong learning for the 21st Century. Pretoria: Department of Education. Pretoria: Government Printers.

Duggan-Haas D., \& Gallagher, J.J. (2004). Using the Secondary Teaching Analysis Matrix in Science Education Research and Teacher Education. AETS Pre- Conference Workshop on STAM.

Ebiendele, E.P. (2012). Critical thinking: Essence for teaching mathematics and mathematics problem solving skills. African Journal of Mathematics and Computer Science Research , 5(3): 39-43.

Gall, (2013). The Use of Questions in Teaching, http://rer.sagepub.com/content/40/5/707. Retrieved 23-08- 2013.

Gallagher, J.J., \& Parker, J. (1995). Secondary teacher analysis matrix. East Lansing, MI: Department of teacher Education, Michigan State University.

Good, T. L. Brophy, J. E. (2008). Looking in Classrooms, London: Routledge Falmer Department Basic Education (2013). National Curriculum and Assessment Policy (CAPS). Republic of South Africa, Pretoria.

National Council of Mathematics Teachers (1991). Principles and Standards for School Mathematics. http://www.nctm.org /standards/content.aspx?id=16909. Retrieved 23-08-2013.

Ngoepe, M.G. (2004). Secondary mathematics teachers' classroom practices: A case study of three township schools in Gauteng Province, South Africa. Unpublished Doctor of Mathematics Education thesis, Curtin University of Technology, Perth.

Riegle, R.P. (1976). Classifying Classroom Questions. Journal of teacher education, (27) 2: 156-16.

Taylor, N., \& Vinjevold, P. (1999). Getting learning right-report of the Presidents's Education initiative research report. Johannesburg: The Joint Education Trust.

Yin, R.K. (2009). Case study techniques: Design and methods (2nd ed.). Newbury Park, CA: Sage.

Van de Walle, JA, Karp K. S. Bay-Wiliams J.M. (2013). Elementary and middle school Mathematics teaching developmentally, $8^{\text {th }}$ Ed, Boston: Pearson 
